\title{
Cross-cultural pragmatics and audiovisual translation
}

\author{
Marie-Noëlle Guillot \\ University of East Anglia, NORWICH, UK
}

In this article, audiovisual translation is considered contrastively from a cross-cultural pragmatics perspective, in its uses of language across languages and cultures. This inevitably broaches questions of linguistic and cultural representation, critical in a world in which the global availability of cultural products is ever greater. They are a main focus in this paper, with related questions about the development of subtitling and dubbing language as idiosyncratic varieties and expressive media, and implications for representation and its impact on audiences.

AVT research has had many challenges to confront in its early days and these are relatively uncharted territories. Yet current developments like fansubbing and other crowdsourcing activities are redefining the name of the game and heralding significant changes, in AVT practices and in the ways they and the products and responses they generate are accounted for in research (as evidenced in emerging re-evaluations of quality and subjectivity, for example; Pérez-González 2012, 2014). These are central concerns in mapping the way forward.

Keywords: AVT, cross-cultural pragmatics, linguistic/cultural representation, pragmatic situatedness

\section{Introduction}

This chapter approaches audiovisual translation (AVT) from the perspective of cross-cultural pragmatics - the branch of pragmatics that considers language use across languages and cultures from a comparative or contrastive point of view.

A fundamental issue is how interpersonal meaning and narrative texture are conveyed interlingually through AVT practices, specifically here subtitling and dubbing. Linguistic and pragmatic specificities of source and target languages are determining factors, as are the standard constraints affecting language choice in these modalities - space and time, synchrony, the intersemiotic shift from speech to writing and legibility for subtitling, 
questions of audience design. Dealing with interlingual transfer in AVT from a contrastive pragmatics perspective also inevitably broaches questions of linguistic and cultural representation, critical in a world in which the global availability of cultural products is ever greater and responses to otherness make the headlines almost on a daily basis.

Research into these various aspects has been limited, perhaps because of the challenges it raises in terms of description and empirical testing: there have been few studies of how communicative practices are depicted interlingually in subtitling and dubbing, let alone of the pragmatic impact of these and other forms of interlingual accessibility practices on audiences' responses. Issues are not just interlingual. Film dialogues, as fictional accounts of naturally occurring speech harnessed to film narratives, are themselves representations, albeit intralingual. Central to a cross-cultural approach to the pragmatics of AV text is thus the task of capturing the complex three-way relationship between naturally occurring speech and its representations in source and target fictional texts/dialogues. Related questions about subtitling and dubbing as idiosyncratic language varieties and expressive media in their own right and their implications for representation and audience responses are also critical in this review.

The first section maps out main features of pragmatics and cross-cultural pragmatics approaches to AVT from the two main perspectives outlined above, narrative texture and linguistic and cultural representation, as a preamble for considering the challenges they raise, and their potential for AVT as a field, in the light of the new developments that have been rocking its foundations and norms. What is arguably at stake is a reconceptualization of AV texts as texts with a capacity to establish their own pragmatic settings, thus a diverse and flexible potential to alert to otherness, increasingly in evidence in emergent crowdsourcing practices. 


\section{Pragmatics and cross-cultural applications to audiovisual translation}

\subsection{Linguistic background}

Pragmatics is concerned with how language is used in social contexts and how participants in communicative situations generate (convey and manipulate) meaning, and comprises four main areas of study: the study of speaker meaning (what speakers convey), of contextual meaning (what the context conveys), of how more gets communicated than is said, and of the expression of relative distance (Yule 1996, 3). All are potentially a locus of difference when attention is on how meaning is constructed by speakers from different cultures, i.e. approached cross-culturally.

From this cross-cultural perspective, which Yule describes for pragmatics as "the study of differences in expectations based on cultural schemata" (Yule 1996, 87), speakers' cultural preferences may thus need to be completely reassessed across linguistic and cultural contexts, from any of the different angles of approach or theoretical underpinnings that have shaped pragmatics since it developed as a subfield of linguistics in the 70s: Gricean pragmatics, with its underlying principle that people involved in conversation cooperate with each other in most circumstances (Grice 1975) - is that so in all languages or cultures? -, and related questions of implicature and relevance, speech act theory (Searle 1969) - how are speech acts and speech events like greeting, thanking, apologising, requesting, etc. enacted, linguistically realised and responded to across languages and cultures? -, conversation analysis (CA) and turn-taking and repair practices (Sacks et al. 1974) - who talks when, what is the value of e.g. silence, interruption or overlap in verbal exchanges, how are they oriented to in different contexts, is the socially prescribed right to talk in any case in evidence in all? -, politeness theory (Brown and Levinson 1987) and face-saving practices (one's own and that of others), 
with later (less ethnocentric) developments making greater room for situatedness and the local negotiation of rapport (e.g. Spencer-Oatey 2000 and others).

Not all can be covered here, and accounted for in full, but this bird's eye view is an index of the diverse types of studies that communicative practices in film dialogues and their interlingual representations can apply to, and of the broad range of features they may encompass. This is also illustrated in the types signposted for debate in contrastive pragmatics work, on politeness, for example: greater or lesser preference for positive or negative politeness in given societies, tolerance of small talk and phatic exchange, reliance on routine formulas, conventional usage of formal and informal pronouns of address, honorifics and personal reference in general, preferences for conventional or non-conventional politeness, the choice of a particular language (from Hickey and Steward 2005, 1). More generally, directness/indirectness is a commonly recognized candidate for difference across cultural contexts and value systems, and one of five dimensions of cross-cultural difference between English and German, for example (with orientation towards self vs. other, content vs. addressees, explicitness vs. implicitness, ad hoc formulation vs. verbal routines) (House 2005).

\subsection{Applications to AVT - concerns, methodologies, basic issues}

In AVT, there are two main types of studies involving pragmatics, de facto cross-culturally when transfer is interlingual:

- Studies that explicitly identify themselves by reference to pragmatics concerns and frameworks, more or less broadly - Hatim and Mason's early 1997 milestone study on politeness in screen translating and, for example, Bonsignori et al. 2011 (greetings, leave-taking and good wishes in dubbing), Bruti 2009a, 2009b (compliments and insults, subtitling and dubbing), Chaume 2004 (discourse markers, subtitling and dubbing), 
Desilla 2012 (implicature), Greenall 2011 (swearing and implicature, subtitling), Guillot 2007, 2010 (orality and interpersonal address, subtitling), Mattson 2009 (discourse particles, subtitling), Pavesi 2009a, 2009b, 2014 (orality, pronominal reference, demonstratives, dubbing), Pinto 2010 (advice, subtitling) -, still relatively few by comparison with work on other aspects like culture specific reference.

- Studies that integrate a pragmatics dimension incidentally, explicitly or implicitly, like the many devoted to dialects and non-standard language varieties, where sociocultural factors inevitably link to language in use in specified contexts and thus pragmatics, or to humour or to orality features in subtitles, e.g. Forchini 2013 (familiarizers, dubbing), Longo 2009 (dialects, subtitling), Matamala 2009 (interjections, dubbing), Romero Fresco 2009 (naturalness, dubbing). Studies of this type are more widespread but more piecemeal.

The examples below focus primarily on the first type, by way of giving an overview of the kinds of concerns addressed, objectives pursued and methodologies, with work illustrating two different approaches. They initially apply just to subtitling, where features of the medium magnify concerns.

\subsection{Case and corpus-based studies, from narrative texture to cross-cultural representation}

Both examples relate to the theme of politeness, the mainstay of most AVT studies with a pragmatics underpinning, in its general technical sense as all aspects of language usage that serve to establish, maintain and modify interpersonal relationships between text producer and text receiver

In the first example, Hatim and Mason's (1997) landmark case study for subtitling, politeness is dealt with as an integrated phenomenon, to assess how interlingual pragmatic shifts may 
affect characterization and film narrative. Hatim and Mason consider how the interpersonal dynamics between characters is depicted in source dialogues and their subtitles, and conclude that the dynamics created in subtitles may be substantially different from that originally intended $(1997,89)$. This is traced, in their case study, to differences in the textual encoding of politeness: in lexical choices, sentence form (imperative, interrogative), unfinished utterances, intonation, ambiguity of reference in the dialogue of the French film Un coeur en hiver (Sautet 1992), and in their cumulative implicated meaning. Thus in the utterances shown below under example (1), elided sequences in the source dialogues become spelt out in the subtitles, hesitation features are omitted, questions turn into assertions. Tentativeness morphs into assertiveness and, for Hatim and Mason, a completely different politeness strategy, for the character depicted, from the off-record self-effacing defensiveness in evidence in the ST, where it deflects the direct threat to face strategy his female protagonist uses to provoke him.

(1) (from Un coeur en hiver) (Hatim and Mason 1997, 85)
i. $\quad$ oui $\boldsymbol{m} \ldots$
[yes b...]
ii. vous n'avez pas joué un peu vite? [did you not play a little fast?]
iii. oui si ça ne ... [yes if it $d_{\text {neg... }}$ ]
Yes, but ...
You took it a bit fast.
iv. $\quad$ non mais $\mathrm{j} . .$. je dois vous laisser travailler. Au revoir. [no but Ielided... I must let you work. Good If you wouldn't mind. bye]
No, I must let you work. Good bye.

In the second example, Pinto (2010)'s study of advice in English subtitles of Spanish films, the focus - on speech acts - is more specific. The objective is also different and overtly cross- 
cultural. Pinto addresses a specific question: why students in the U.S. should comment, after viewing films from Spain, that Spaniards seem vulgar and rude. He analyses 218 occurrences of advice in a corpus of twelve contemporary films in Spanish, and concludes that there is unintended impoliteness in the subtitles in English. This is shown to result from the following main factors: increased level of directness and elimination of mitigating elements in the shift from oral dialogue in Spanish to written subtitles in English, as shown in example (2) below for two of the five types of feature analysed (Head Act and downgrader to the Head Act). In (2) i. there is a change of category in the expression of the speech act verb (Head Act) from what is termed "conventionally indirect" to "strong direct" - with a shift from a question in the negative proffering advice indirectly to a direct order imperative. In (2) ii. there is no downgrader mitigating the suggestion performed:

(2) (from Mataharis and Tiempo de tormenta respectively) (Pinto 2010, 267-8)

i. ¿Por qué no te pones las gafas? Put your glasses on [Why don't you put your glasses on?]

ii. A lo major si tuvieras otro hijo [Maybe if you had another child.]

If you had another baby

The resulting directness, traced to the deletion of mitigating features and form shifts, is at odds with English practices, where prototypical requests and face threatening acts are documented as conventionally indirect, and often rely on multiple downgraders to reduce levels of imposition (Pinto 2010, 259-262). This directness is the by-product of modality constraints and does not reflect the source Spanish either, however, and fuels Pinto's concern that speakers of Spanish may be unwittingly stereotypically perceived as rude.

These examples, of a case study and a corpus-based study, the first dealing primarily qualitatively with politeness as an integrated phenomenon in situated dialogue in one film, 
the second primarily quantitatively with a particular speech event across several, represent two standard types of approach, typical of AVT research generally.

While they harness pragmatics to different ends and are interested in the implications of intermedial and interlingual shifts for different reasons, they identify similar types of modality-related issues. Reduction is the most conspicuous for subtitling and a main factor affecting pragmatic encoding in AVT, one of several cumulatively shaping the cross-over of pragmatic conventions and representation, and debates about them.

\section{Limiting factors}

As ever with subtitling, a core issue is that encoding politeness features (or humour, orality, etc.) often takes more words than there is room for on screen in the time available for display or than are needed to safeguard readability. As widely documented (e.g. in Hatim and Mason 1997), the first elements to be sacrificed are linguistic features with expressive and pragmatic value or functions but no clear overt meaning, as in (2) and (1) iii. and iv. above, with simplicity also preferred - shifts from complex to simple syntactic structures, for example, like the shift to direct imperative in (2) i., and to a simple assertion from a mitigated question in the negative in (1).

The overarching concern for AVT from a pragmatics perspective is encoding, however, and the forms it may take. While space and related constraints may call for reduction, other considerations like legibility, may result in simplification, as just noted, or expansion, as seen in examples (1) i. and iii. where elided source items are expanded to full forms in the target text, with comparable impact on characterisation and narrative. Both expansion and reduction in this case cumulatively contribute to the politeness shift when considered cross-culturally, with the other features also discussed above - shift from question to assertion, from negative to affirmative. 
Additional factors documented to promote idiosyncratic pragmatic representation in both source and target dialogues include audience design and the need to keep discourse coherent, both for exchange participants on-screen (diegetically) and to keep overhearing audiences in the loop. This point, highlighted in Hatim and Mason's contextualised analyses, magnifies the critical relevance of the broader (linguistic and non-linguistic) prior context for local choices. Their pragmatic import is returned to in the next section.

Tensions between source and target dialogues run deeper than reduction and encoding, and raise questions which have yet to be fully addressed in the field, but have been covertly raising their heads in observations across explicitly and implicitly pragmatics studies, and subtitling and dubbing. Bruti has dealt with both, with application to the compliment speech act in subtitling (2009a; 7-film corpus) and to compliments and insults in dubbing (2009b; Pavia corpus), in hybrid studies of narrative texture and representation, and provides other kinds of insights in these respects. She, too, identifies a marked preference for omission and reduction in subtitling, but nuances this with additional observations. Like Pinto, she points to interlingual representational shifts, in the focus of compliments, for example (from performance in English to personal qualities in Italian, e.g. 'That was great' to 'Sei stata grande' [you were great]; from Tootsie, Bruti 2009a, 232), in this case adapted to TL practices. Her comments also draw attention to distinctive uses of language in film contexts and to the locally negotiated thus contextual nature of politeness therein: to a more varied repertory of linguistic expressions in representing compliments than the few stereotypical formulae identified in sociolinguistic studies; to the recurrence of some adjectives (like 'brilliant', 'cute', 'terrific') (and lesser frequency of semantically vague adjectives like 'nice'); to greater explicitness in the target text in some cases, reinforcing what is conveyed visually or paralinguistically in the source, and translating the global essence of the original text rather than a local chunk (Bruti 2009a, 238). For dubbing she further stresses, with 
standard issues of lip synchrony, the likelihood of misapprehensions of pragmatic value when politeness/impoliteness markers are dealt with out of context: politeness, as situated and locally negotiated, need to be considered in whole interactions rather than just individual speech acts or utterances (in line with recent theory; e.g.insults can create rapport in some contexts) (Bruti 2009b, 163).

Situatedness, idiosyncratic nature of AV language in filmic contexts, pragmatics shifts and their impact on narrative texture and linguistic representation: in these broad factors outlined with this sample overview of studies with an explicitly pragmatic perspective are encapsulated both the challenges and the potential of film and AVT language. They are addressed next in terms of the fundamental debates they embody, and as a platform for mapping the way forward.

\section{The pragmatics of AV texts: challenges and potential}

\subsection{Pragmatic and representational shifts - the conundrum of cultural a-synchrony}

The first debate is captured in the challenges of cultural a-synchrony ${ }^{1}$, always present, rarely addressed explicitly. A core issue is the extent to which target texts mirror source text practices, or are adapted to target communicative preferences and expectations, i.e. 'domesticated' for target audiences, a basic dilemma in Translation Studies. It is contentious either way.

The inescapable co-presence of a context associated with a particular language and culture (e.g. Spanish in Pinto, English in Bruti above), and target text in a language in which verbal practices and orientations may be different (English in Pinto, Italian in Bruti), inevitably

\footnotetext{
${ }^{1}$ Term used in Manhardt 2000 to refer to te cultural mismatch between the source languages and cultures seen and/or heard on scre in films and representations in target languages.
} 
raises questions whatever strategy is used. Is it appropriate to assign to native speakers of English the practices of speakers of Italian, for example, as in the case with compliments and the focus shift discussed in Bruti, thus to lead audiences to a) assume that there is a match across English and Italian, and b) respond in relation to expectations set by their own language and experience? The practice, acknowledged as common in dubbing (Pavesi 2014) has, at worst, been robustly reproved as "corrupt" (Nornes 1999). On the other hand, what is at stake when the practices depicted are at odds with TL practices and expectations is laid bare in Pinto's examples and stereotyping concerns, aggravated when practices are also at odds with source dialogues' representations. It is expressed in the simple question he raises: what is a 'good' subtitle or 'good' dubbing practice from a pragmatics perspective? For Pinto, an utterance that is not taken as impolite in the source language should not become impolite in the target language (Pinto 2010, 271). How is this (to be) achieved, and how is it dealt with in practice, in view of cultural a-synchrony and modality constraints? What is the extent, and impact on audiences, of pragmatic acculturation, and of pragmatic misrepresentation? How could/should resulting considerations inform translators' practices? This basic conundrum for pragmatics approaches to AVT sets the agenda for research: we are a long way from having enough empirical data to cope with the questions it begs and reliably to inform discussions. On the other hand, the work currently emerging and overtly or covertly casting further light on the nature of AV language has been paving the way forward, with both caveats to be mindful of and alternative outlooks on staple issues. Loss is one, representational capacity another.

\subsection{Audiovisual language in filmic contexts - the 'other' space of language}

The second main debate sets the ubiquitous question of loss against linguistic creativity. Loss in AVT is inevitable - a de facto by-product of technical and multimodal synchrony 
constraints, and cross-linguistic and cross-cultural difference. Inevitably also, subtitling and dubbing language has a life of its own, like film language generally. All mirror naturally occurring speech to an extent. They also have a creative potential that is part and parcel of achieving narrative efficiency in highly constrained contexts, with all this entails: producing effective spoken aloud fictional written exchanges with extradiegetic functions for audiences, the additional twist of the intersemiotic shift back to writing for subtitling and lip-synchrony for dubbing, and need to be attuned to what is otherwise conveyed visually and aurally in the multimodal context of films. This idiosyncracy, broadly acknowledged in most AVT studies, may prove to be as much a gift for representation as the plight it has been seen to be in loss debates.

Empirical evidence has been building with corpus work and (four-way) systematic comparisons of naturally occurring speech and film dialogues in source and target languages. It is gradually providing a picture of degrees and patterns of (mis-)alignment, and a platform for appraising their implications for intra and interlingual representation (see Baños et al. 2013 and Freddi and Pavesi 2009's volumes showcasing work with the Forlì and Pavia corpora of AV texts, for example). Creative specificity is seen in the capacity of selected target language features to express pragmatic meaning and sociolinguistic variation symbolically as drawn to attention by Pavesi for dubbing across a range of features, for example: as non-random privileged carriers of orality (2009a), markers of otherness (pronominal use, 2009b), sites of cross-linguistic variation (demonstratives, 2014). For subtitling it is illustrated in the archetypal 'Carla? Where's Le Henry?' example discussed in Guillot (2010, 2012) (from Sur mes lèvres, Audiard 2001), and the internal pragmatic settings it draws to attention, achieved by an interplay of different features, including punctuation: the Christian name mode of address and the first question mark and associated rising intonation and pause give the prompt for attention a caring attentiveness that 
pre-mitigates the ensuing request and deflects from taking its overt formal directness at its face value (compare with ‘Carla where's Le Henry?' or 'Where's Le Henry’). Possible misguided perceptions of communicative practices in the source language are thus kept at bay (of French as direct and rude in relation to English): as in Pinto's examples for advice, the source dialogue request is in fact overtly and heavily mitigated (Carla/ je vous demandais où était Le Henry/ [Carla/ I was asking you where le Henry was]).

In all this, and as underscored in Pavesi, non-randomness is key: internal pragmatic settings depend on the cumulative impact of features working together in integrated combinations, in this instance on the markedness of the first name address 'Carla', a conspicuous shift at this point from the 'Miss Behm' title+surname address used until then by the same locutor as the expected mode in the French work context and for the type of relationship depicted (boss/PA). This is situatedness, but different in nature from the locally contextual kind alluded to for individual interactions in Bruti: it spans the full set of dialogues, with conventions established early on and adhered to and developed throughout (see e.g. Guillot 2010 for cues triggering the experience of T/V pronominal shifts in English from French). This kind of medium situatedness and pragmatic singularity is also built in conversational routines with a chiefly phatic role in naturally occurring speech: greetings and leave takings or openings/closings in phone exchanges, when present in film dialogues, are adapted to fulfil the narrative functions that justifies keeping them at all, for example. 'Hi' and 'Hello' can be observed to index internally set types of rapport or circumstances, for example, as shown in a case study of subtitles in two French and one Spanish films (Caché/Hidden, Haneke 2008; Paris, Klapish 2008, Volver, Aldomovar 2006 (Guillot, fc 2016) where greeting scenes are otherwise clearly engineered to set up plots and sub-plots, and their pragmatic settings manipulated to this end. Indexing of this type is a key factor to take into account in the interpretation of both qualitative and quantitative data, like the relative distribution, across 
English ST, dubbed and original film dialogues in Italian, of greeting terms or qualitative asymmetries for greetings/leave takings discussed in Bonsignori et al. 2011).

\section{Pragmatic perspectives in AVT - making linguistic and cultural representation}

\section{matter}

Like film language generally, subtitling and dubbing have a capacity to generate internal systems of pragmatic representation and modes of interpretation, to work as a code in their own right. This capacity can be harnessed to contend with the conundrum of cultural asynchrony and modality constraints, in research and practice. It is possibly also a means of capturing otherness in communicative practices, not literally, but at least in their "pragmatic essence', as the native equivalent of what Yule describes as "pragmatic accent" for nonnativeness $(1996,88)$.

Evidence of this expressive potential of AVT comes up recurrently, in studies with or without acknowledged pragmatic focus, if often only implicitly (e.g. Gartzonika and Şerban 2009 and Longo 2009, for non-standard language and dialects in subtitling as discussed in Guillot 2012, Casarini 2012 (Net lingo, dubbing), De Meao 2012 (dialects, subtitling), Ranzato 2010 (dialects, dubbing), Romero Fresco (features of dubbese, 2009) and others). It is also given an expression and greater latitude in fansubbing/fandubbing amateur interventionist mediation, for better or for worse, but in a recognised challenge both to practices and to the notion of quality as generated from an audience base (Pérez-González 2012).

The pragmatic underpinnings of AV and AVT language are still largely to be mapped out, however, and complex to account for. This brief overview cannot begin to do justice to the multiplicity of factors and features involved, nor to the analytical scope and depth of the work it used as examples. A major contribution of pragmatics approaches has been to bring to AVT research the theoretical and methodological know-how of linguistics, and resources for 
identifying issues and rationalizing observations and findings. Streamlining them to generalizable and functional results is one of the main challenges ahead.

Corpus-based work provides an effective platform for building on the critical insights it has already begun to produce, with contrastive work across naturally occurring speech and its intra and interlingual representations. It will have to be mindful of evidence from situated analyses in full film contexts/dialogues sets, as will cases studies of the misleading tendency to deal with decontextualized text segments. Much more data are needed, however: we need more full transcripts of films dialogues and corresponding subtitles and dubbing, and across more pairs of languages, to remedy the current English/other language asymmetries in evidence in examples here, and to generate enough evidence for a more robust understanding of the representational potential of AVT and its manifestations across speech features and events, genres and languages. A more coordinated effort is also needed to make data accessible to a larger constituency of researchers and achieve the critical mass to make a difference to research, and to its applications.

A crucial step is to document practices and strategies systematically, on their own pragmatic terms, i.e. as experienced by audiences with no access to source dialogues, and by reference to evidence from naturally occurring speech, where available, for a range of activities: to make better critical sense of the pragmatic know-how invested in professional practice (see e.g. Bannon 2013); to inform translator training and the pedagogical use of film materials for FL learning/teaching and training in intercultural communication; as a resource for crosscultural pragmatics itself where evidence is still patchy; to appraise audience responses to linguistic and cultural representation and the impact of foreign films in shaping their publics' sense of otherness. Individual variability and viewers' socio-cultural heterogeneity make reception studies with these objectives methodologically very complex, but they are overdue. Hatim and Mason's early (1997) call for audiences' impressions of interlingually projected 
pragmatic meaning in films to be empirically tested has begun to be heeded (see e.g. Antonini and Chiaro 2009). The multifarious and boundless dissemination of cultural products on the global scene and the imponderables of its cross-cultural influence make the research urgent.

\section{Bio-note}

Marie-Noëlle Guillot is a Senior Lecturer in French, Linguistics and Translation Studies at the University of East Anglia, Norwich, in the UK. Her research in AVT and cross-cultural pragmatics has focused on questions of cross-cultural representation in subtitling. Her publications on the topic include "Film subtitles from a Cross-cultural Pragmatics Perspective: Issues of Linguistic and Cultural Representation.” in The Translator (2010), "Stylization and Representation in Subtitles: Can Less be More?" in Perspectives: Studies in Translatology (2012), “Communicative Rituals and Audiovisual Translation - Representation of Otherness in Film Subtitles" in META (fc 2016, 61.3) Email address: m.guillot@uea.ac.uk

\section{References}

Antonini, Rachele, and Delia Chiaro. 2009. “The Perception of Dubbing by Italian Audiences.” In Audiovisual Translation: Language Transfer on Screen, ed. by Díaz Cintas Jorge and Gunilla Anderman, 97-113. Basingstoke: Palgrave Macmillan. Bannon, David. 2013 [2009]. The Elements of Subtitles: A Practical Guide to the Art of Dialogue, Character, Context, Tone and Style in Film and Television Subtilting. Blackstock: Translation Studies Press. 
Baños, Rocio, Silvia Bruti, and Serenella Zanotti, eds. 2013. Corpus Linguistics and Audiovisual Translation: in Search of an Integrated Approach. Special Issue of Perspectives: Studies in Translatology 21 (4).

Bonsignori, Veronica, Silvia Bruti, and Slivia Masi. 2011. "Formulae across Languages:

English Greetings, Leave-takings and Good Wishes in Dubbed Italian.” In Audiovisual Translation in Close-up: Practical and Theoretical Approaches, ed. by Adriana Șerban, Anna Matamala, and Jean-Marc Lavaur, 23-44. Bern: Peter Lang. Brown, Penelope, and Stephen C. Levinson. 1987. Politeness. Cambridge: Cambridge University Press.

Bruti, Silvia. 2009a. "The Translation of Compliments in Subtitles." In New Trends in Audiovisual Translation, ed. by Jorge Díaz Cintas, 226-238. Clevedon: Multilingual Matters.

Bruti, Silvia. 2009b. "Translating Compliments and Insults in the Pavia Corpus of Film Dialogues: Two Sides of the Same Coin?” In Analysing Audiovisual Dialogue : Linguistic and Translational Insights, ed. by Maria Freddi and Maria Pavesi, 143163. Bologna: CLUEB.

Casarini, Alice. 2012. "XOXO: Gossip Girl and Dubbing in the Age of 'Net lingo'.” In Audiovisual Translation across Europe: An Ever-changing Landscape, ed. by Silvia Bruti and Elena Di Giovanni, 59-78. Bern: Peter Lang.

Chaume, Frederic (2004). "Discourse Markers in Audiovisual Translating”. Meta: 49(4): 843-855.

De Meao, Mariagrazia. 2012. "Subtitling Dialects: Strategies of Socio-Cultural Transfer from Italian into English.” In Audiovisual Translation across Europe: An Everchanging Landscape, ed. by Silvia Bruti and Elena Di Giovanni, 79-96. Bern: Peter Lang. 
Desilla, Louisa. 2012. "Implicatures in film: Construal and functions in Bridget Jones romantic comedies.” Journal of Pragmatics 44: 30-53.

Freddi, Maria and Maria Pavesi, eds. 2009. Analysing Audiovisual Dialogue: Linguistic and Translational Insights. Bologna: CLUEB.

Forchini, Pierfranca. 2013. “A Diachronic Study of Familiarizers ('man', 'guys', 'buddy', ‘dude’) in Movie Language.” Perspectives: Studies in Translatology 21 (4): 504-525.

Gartzonika, Olga and Adriana Şerban. 2009. “Greek Soldiers on the Screen: Politeness, Fluency and Audience Design in Subtitling." In New Trends in Audiovisual Translation, ed. by Jorge Díaz Cintas, 239-250. Clevedon: Multilingual Matters.

Greenall, Annjo K. 2011. "The non-translation of swearing in subtitling: Loss of Social Implicature?" In Audiovisual Translation in Close-up: Practical and Theoretical Approaches, ed. by Adriana Şerban, Anna Matamala, and Jean-Marc Lavaur, 45-60. Bern: Peter Lang.

Grice H. Paul. 1975. "Logic and conversation.” In Speech Acts, ed. by Peter Cole and Jerry Morgan, 41-58. New York: Academic Press,.

Guillot, Marie-Noëlle. 2007. "Oral et illusion deoral: indices d'oralité dans les sous-titres de dialogues de film.” META, 52 (2): 239-259.

Guillot, Marie-Noëlle. 2010. "Film subtitles from a Cross-cultural Pragmatics Perspective: Issues of Linguistic and Cultural Representation.” The Translator, 16 (1): 67-92. Guillot, Marie-Noëlle. 2012. "Stylization and Representation in Subtitles: Can Less be More?” Perspectives: Studies in Translatology Perspectives: Studies in Translatology 20 (4): 479-494.

Guillot, Marie-Noëlle. [submitted Target] "Communicative rituals in film dialogues and their subtitles - what representation of otherness"

Hatim, Basil and Ian Mason. 1997. The Translator as Communicator. London: Routledge. 
Hickey, Leo and Miranda Stewart. 2005. Politeness in Europe. Clevedon: Multilingual Matters.

House, Juliane. 2005. "Politeness in Germany: Politeness in Germany?" In Politeness in Europe, ed. by Leo Hickey and Miranda Stewart, 13-28. Clevedon: Multilingual Matters.

Longo, Abele. 2009. "Subtitling the Italian South.” In New Trends in Audiovisual Translation ed. by Jorge Díaz Cintas, 99-108. Clevedon: Multilingual Matters.

Manhart, Sibylle 2000. “'When worlds collide': Betrachtungen über fremde Kulturen im filmtranslatorischen Handlungsgefüge" In Translationwissenschaft: Festschrift für Mary Snell-Hornby zum 60. Geburtstag, ed. by Mira Kadric, Klauz Kaindl and Franz Pöchacker, 167-181. Tübingen: Stauffenburg Verlag,

Matamala, Anna. 2009. "Interjections in Original and Dubbed Sitcoms in Catalan: A Comparison". Meta, 54(3): 485-502.

Mattson, Jenny. 2009. The Subtitling of Discourse Particles. A Corpus-Based Study of Well, You Know, I Mean, And Like, and their Swedish Translations in Ten American Films. Unpublished PhD thesis, University of Gothemburg, Gothemburg, Sweden.

Nornes, Abé Mark. 1999. "For an abusive subtitling” Film Quarterly. 52 (3), 17-34.

Pavesi, Maria. 2009a. "Dubbing English into Italian: a Closer Look at the Translation of the Spoken Language.” In New Trends in Audiovisual Translation, ed. by Jorge Díaz Cintas, 197-209. Bristol: Multilingual Matters.

Pavesi, Maria. 2009b. "Pronouns in Film Dubbing and the Dynamics of Audiovisual Communication.” VIAL - Vigo International Journal of Applied Linguistics, 6: 89107.

Pavesi, Maria. 2014. This and That in the Language of Film Dubbing: a Corpus-Based Analysis. Meta 58 (1): 107-137. 
Pérez-González, Luis. 2012. “Amateur Subtitling and the Pragmatics of Spectatorial Subjectivity. Language and Intercultural Communication, 12 (4): 335-353.

Pérez-González, Luis. 2014. Audiovisual Translation: Theories, Method and Issues. London: Routledge.

Pinto, Derrin. 2010. "Lost in subtitle translations: The case of advice in the English subtitles of Spanish films.” Intercultural Pragmatics, 7 (2): 257-277.

Ranzato, Irene. 2010. "Localising Cockney: Translating Dialect into Italian. In New Insights into Audiovisual Translation and Media Accessibility: Media for All 2, ed. by Jorge Díaz Cintas, Anna Matamala, and Josélia Neves, 109-122. Amsterdam: Rodopi.

Romero Fresco, Pablo. 2009. "Naturalness in the Spanish Dubbing Language: a Case of Not-soclose Friends." Meta 54: 49-72.

Sacks, Harvey, Emanuel Schegloff and Gail Jefferson. 1974. "A Simplest systematics for the organisation of turn taking for conversation.” Language 50: 696-735. Searle (1969).

Spencer-Oatey, Helen, ed. 2000. Culturally Speaking: Managing Rapport through Talk across Cultures. London: Continuum.

Yule, George. 1996. Pragmatics. Oxford: Oxford University Press. 